\title{
ALTERAÇÃO DO PROGRAMA DE ADIÇÃO DE ESCORIFICANTES PARA MELHORIA DA ESPUUMAÇÃO DA ESCÓRIA E REDUÇÃO DE CONSUMO DE ENERGIA ELÉTRICAA NO FEA DA VSBM*
}

\author{
Lívia Lopes de Oliveira Goulart ${ }^{1}$ \\ André Luiz Vasconcellos da Costa e Silva ${ }^{2}$ \\ Ely da Silva Araújo Junior ${ }^{3}$
}

\begin{abstract}
Resumo
A prática de escória espumante ganhou o mundo dos fornos elétricos a arco por apresentar muitas vantagens, dentre elas a redução das perdas térmicas do arco elétrico para o ambiente, reduzindo o consumo de energia elétrica e também permitindo uma maior recuperação do metal perdido em forma de FeO para a escória através da reversão feita com a injeção de $\mathrm{C}$. No entanto, a eficiência das escórias espumantes produzidas atualmente ainda é tema de estudo para aqueles que querem melhorar a eficiência do processo, a vida do equipamento e reduzir custos de elaboração. Assim, esse trabalho tem como objetivo otimizar as propriedades da escória através do ajuste da saturação em $\mathrm{MgO}$, melhorando a eficiência da escória espumante e reduzindo a perda de $\mathrm{Fe}$ sob a forma de FeO. O resultado das alterações realizadas foram ganho de energia elétrica medido e redução da perda de rendimento metálico do FEA, obtida comparando o peso produzido e o esperado pela carga metálica.
\end{abstract}

Palavras-chave: Escória Espumante; FEA; Energia Elétrica; Rendimento Metálico.

\section{CHANGES IN THE SLAGGING ADDITIONS TO IMPROVE SLAG FOAMING AND DECREASE THE CONSUMPTION OF ELECTRIC ENERGY IN VSBM EAF \\ Abstract}

Foaming slag practice has been widely accepted in electric arc furnace due to its many advantages. Some are the reduction of heat losses from the arc to the environment, which decrease the consumption of electricity, and making possible a larger recovery of iron from the slag $\mathrm{FeO}$ through reduction by $\mathrm{C}$ additions. However, there is still a large field of study related to the proper foaming conditions for those wanting to improve process efficiency, furnace life and decrease tap-to-tap times. Thus, this paper aims the slag properties improvement through $\mathrm{MgO}$ saturation of the slag, increasing the foaming efficiency and reducing the losses of iron in the form of slag $\mathrm{FeO}$. The changes introduced in the process resulted in a reduction in the electric energy consumption and an increase in the iron yield of the EAF based on a comparison of the produced weight and the charge weight.

Keywords: Foaming slag; EAF; Electric Energy; Metallic Yield..

1 Engenheira Metalúrgica, Eng. de Processos da Aciaria Elétrica, VSBM, Barra Mansa, RJ, Brasil; livia.goulart.Ig1@vsiderurgia.com.br.

2 Engenheiro Metalúrgico, PhD, Professor, EEIMVR, UFF, Membro da ABM, Volta Redonda, RJ, Brasil; andre@metal.eeimvr.uff.br

3 Engenheiro Metalúrgico; M.Eng., Gerente da Aciaria Elétrica, VSBM, Resende, RJ, Brasil; ely.araujo@vsiderurgia.com.br. 


\section{INTRODUÇÃO}

Garantir eficiência energética em um Forno Elétrico a Arco (FEA) e manter níveis baixos de FeO dissolvido na escória (duas práticas importantes na redução de custos de produção das aciarias elétricas), são objetivos fundamentais e requerem elevado conhecimento e controle do processo. Melhorias nestas áreas permitem reduzir os custos, aumentar a produtividade e melhorar a estabilidade do processo, além de aprimorar o processo de fabricação dos aços longos de forma a manter o produto competitivo no mercado, garantindo a lucratividade do negócio, e a sobrevivência em períodos de crise.

Uma boa prática da escória espumante é eficaz na melhoria dos dois aspectos em questão.

Segundo Àvila T.A. [1], a escória espumante foi criada para diminuir a dissipação de calor através de radiação, som e as perdas de gases ligadas a injeção de $\mathrm{O}_{2}, \mathrm{C}$ e combustível. O principal objetivo foi reduzir o consumo de energia elétrica (EE). Além disso, a prática de escória espumante também protege o refratário e pela melhoria de rendimento do processo, reduz o tempo de processamento do FEA.

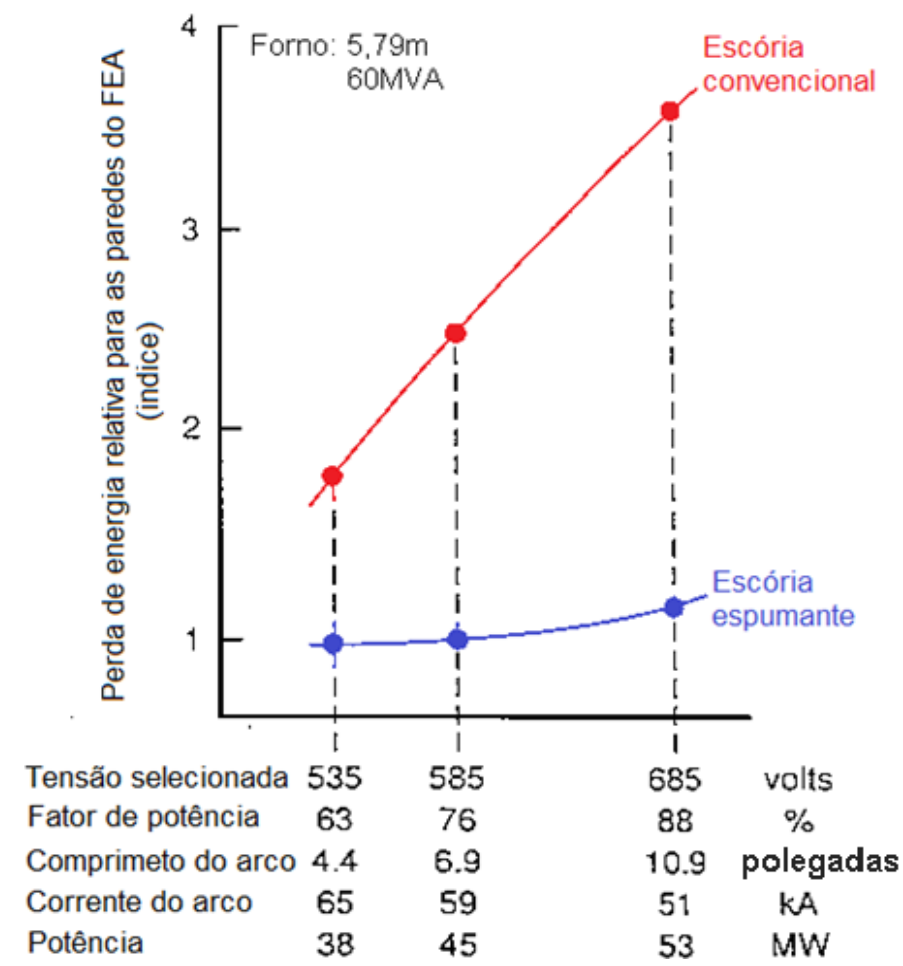

Figura 1. Perdas térmicas relativas para as paredes do forno em função da espumação da escória. Adaptado de Jones, J.A.T et al [2]

A eficiência térmica com escória espumante fica em torno de $60-90 \%$ enquanto sem ela chega somente a $40 \%$.

Para garantir uma boa escória espumante, é necessário garantir viscosidade adequada [3,4] garantindo uma porção líquida da escória com correta fração de sólidos na mistura. Em geral, adições de fundente a base de MgO para produzir a saturação adequada em magnesiowustita, são a solução desejada. Segundo Pretorious, E. e Oltmann, H.[5] a viscosidade da escória influencia também a possibilidade de reversão eficaz do $\mathrm{FeO}$ para Fe no banho metálico. Por fim, foi determinado que, para cada basicidade, a condição ótima de adição de $\mathrm{MgO}$ para 
espumação, é diferente (Figura 2). Naturalmente a temperatura e a presença de outros óxidos também influencia esta condição de espumação ótima.

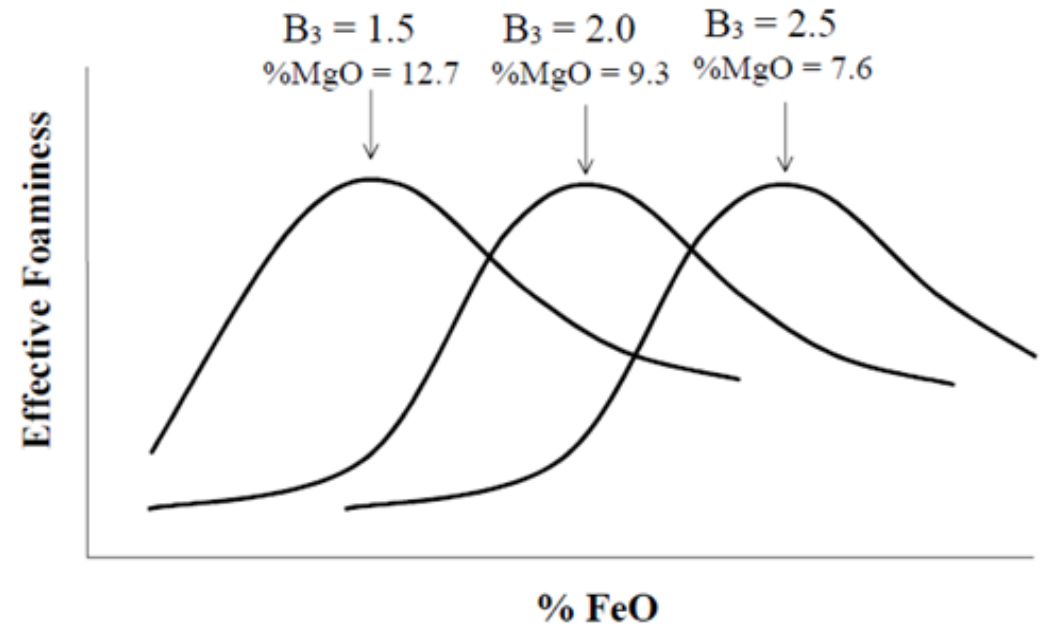

Figura 2. Curvas de basicidade e \% $\mathrm{MgO} \times \% \mathrm{FeO}$ formado e eficiência da espumação da escória. Adaptado de Pretorious, E. e Oltmann, H. [5]

A Figura 2 indica que para basicidades binárias mais baixas é possível obter condições ótimas de espumação com menores teores de $\mathrm{FeO}$ na escória mesmo que adição de $\mathrm{MgO}$ precise ser algo maior.

Assim, neste trabalho, busca-se determinar, as adições ideais de $\mathrm{MgO}$ na formação de escória espumante com basicidades na faixa de 1,5, medindo-se o efeito desta adição sobre o rendimento metálico e redução do consumo de EE. Assim, se visa definir um novo programa de adições de fundentes pelo quarto furo do FEA da VSBM.

\section{MATERIAIS E MÉTODOS}

\subsection{Avaliação do FeO:}

Para avaliar a quantidade de FeO na escória, foram levantados os parâmetros que devem ser influenciados por esta variável:

a) Quantidade de $\mathrm{O}_{2}$ livre - Oxigênio que combina, de fato, com os elementos químicos no FEA, realizando as reações de oxidação e portanto, a formação de $\mathrm{FeO}$, entre outros óxidos;

b) Quantidade de Coque - esta quantidade está diretamente ligada à formação de $\mathrm{CO}$ na espumação da escória e consequente reversão de Fe presente no FeO da escória para o banho;

c) \% MgO e B2 na escória - duas características listadas na literatura [2] como críticas para a obtenção de boa espumação e capazes de facilitar a reversão do FeO para Fe no banho metálico.

\subsection{Avaliação da Escória:}

Para a avaliação da escória, foram coletados dados de 36 escórias, de início e fim de refino de aços ABNT 1012 e 1026. A primeira amostra foi retirada logo no início da escorificação da corrida (1- amostra de início de refino) a segunda ao final do refino (2-amostra final de refino).

As escórias foram analisadas por Espectrometria de Raios-X na unidade de Resende da Votorantim Siderurgia. 
A partir dos resultados obtidos, foi proposto um novo programa de adição de escorificantes para o FEA da VSBM.

\section{RESULTADOS E DISCUSSÃO}

Várias correlações entre a composição da escória e a adição de oxigênio foram verificadas, de modo a definir qual a melhor estratégia de adição de escorificantes. Estas correlações são apresentadas a seguir.

\subsection{Avaliação do $\mathrm{FeO}$ em relação ao 02 livre}

O efeito da variável $\mathrm{O} 2$ livre sobre o teor de $\mathrm{FeO}$ na escória é apresentado na Figura 3. Percebe-se que, de fato, quanto maior é o $\mathrm{O}_{2}$ livre, maior também é o FeO:

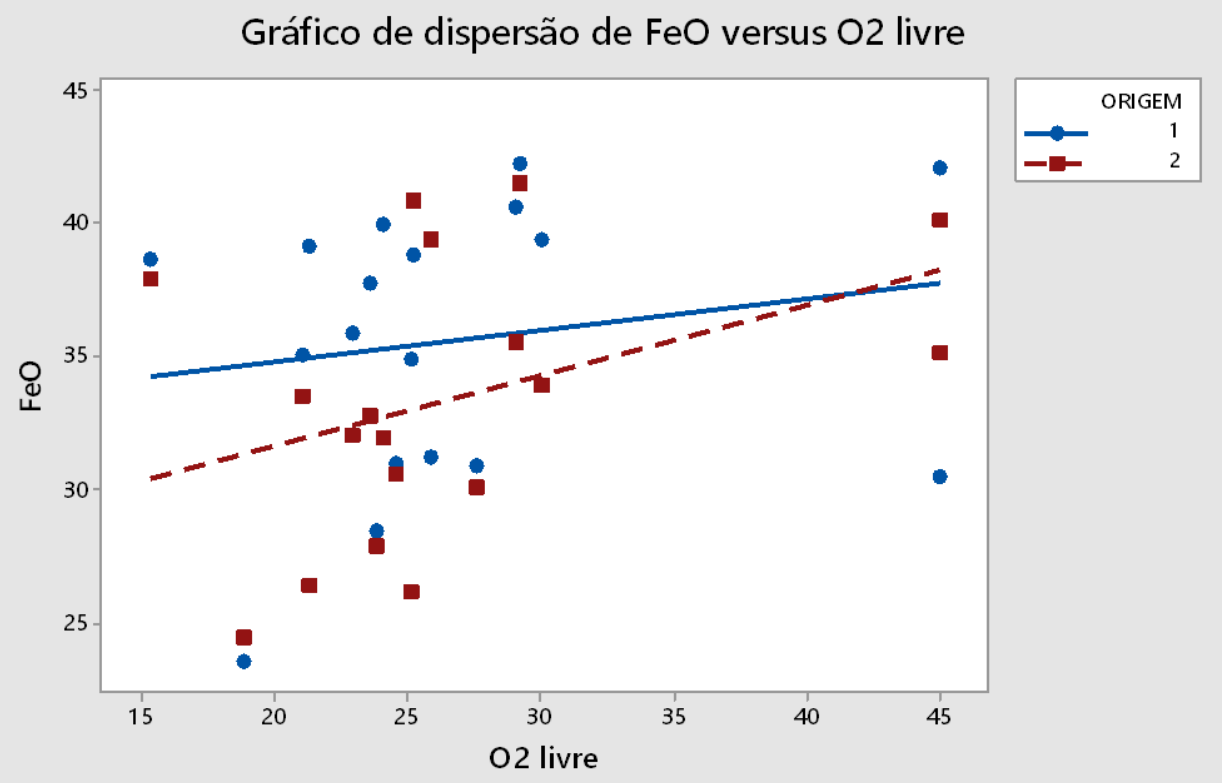

Figura 3. Influência do O2 livre no \%FeO da escória. (1- amostra de início de refino) (2-amostra final de refino).

É possível verificar que os níveis de $\mathrm{O}_{2}$ livre no banho estão entre 20 e $30 \mathrm{Nm}^{3} / \mathrm{t}$, o que resultaria em teor de $\mathrm{FeO}$ em torno de $31 \%$ no final do refino e em torno de $34 \%$ no início do refino, valores esses que garantem baixas perdas de rendimento no FEA.

\subsection{Avaliação do FeO em função do Coque}

Conforme o esperado, quanto maior a quantidade de coque, maior a reversão do FeO para o banho metálico. 


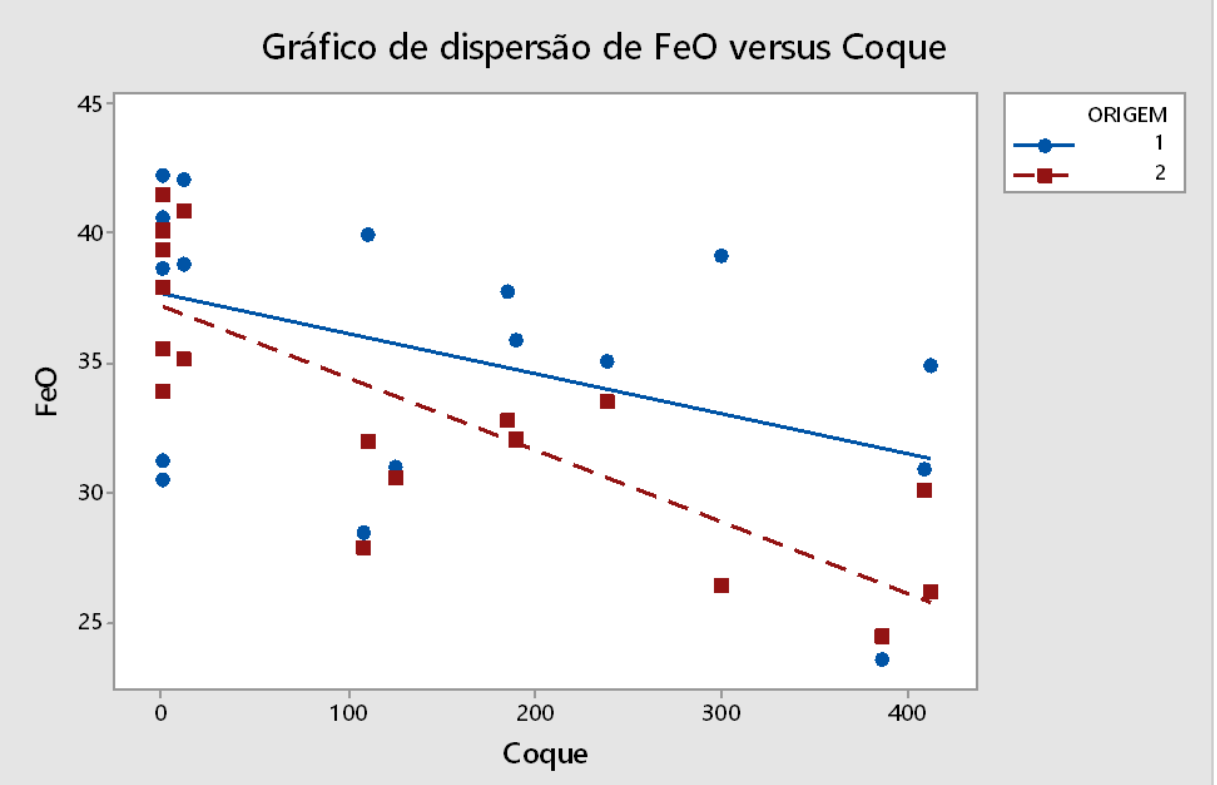

Figura 4: Influência do coque no \%FeO da escória. (1- amostra de início de refino) (2-amostra final de refino).

Com a prática atual de injeção automática de coque no final dos carregamentos, temse injeção média de $300 \mathrm{~kg}$ por corrida, o que dá um $\mathrm{FeO}$ de $28 \%$ no fim de refino e $35 \%$ no início do refino. Esses valores garantem também, bom rendimento no FEA.

\subsection{Efeito do \% MgO e B2 na escória sobre o FeO}

A Figura 5 mostra a importância destas variáveis sobre o comportamento e recuperação do $\mathrm{FeO}$ da escória GAE VSBM.

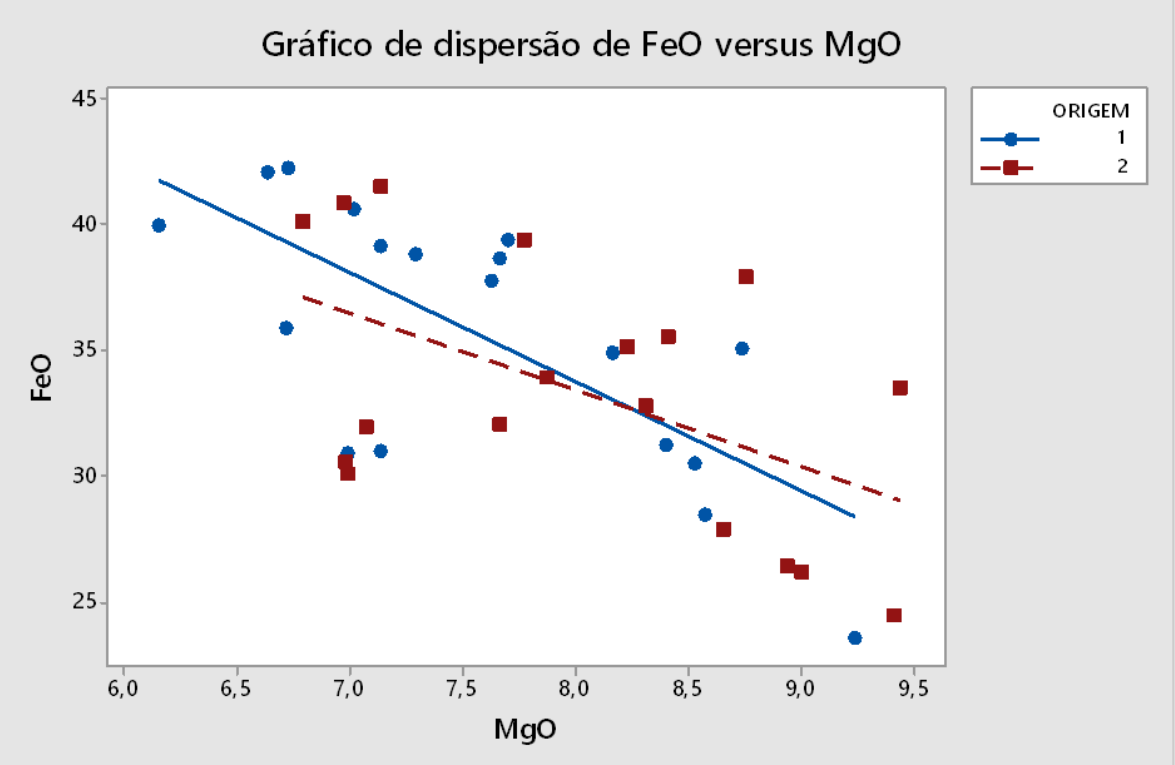

Figura 5: Influência do \%MgO no \%FeO da escória. (1- amostra de início de refino) (2-amostra final de refino).

É possível observar que, com $\mathrm{MgO}$ próximo a 9,0\%, tem-se $\mathrm{FeO}$ de final de refino próximo a $28 \%$ e de início de refino de $31 \%$. Com a análise atual da escória, o $\mathrm{MgO}$ medido no processo da GAE VSBM é de $8 \%$, o que não permite alcançar níveis de $\mathrm{FeO}$ tão baixos. 
A partir da avaliação da figura 2, também se observa que quanto maior a B2, maior é a quantidade de FeO retida nela, como é possível verificar na figura 6.

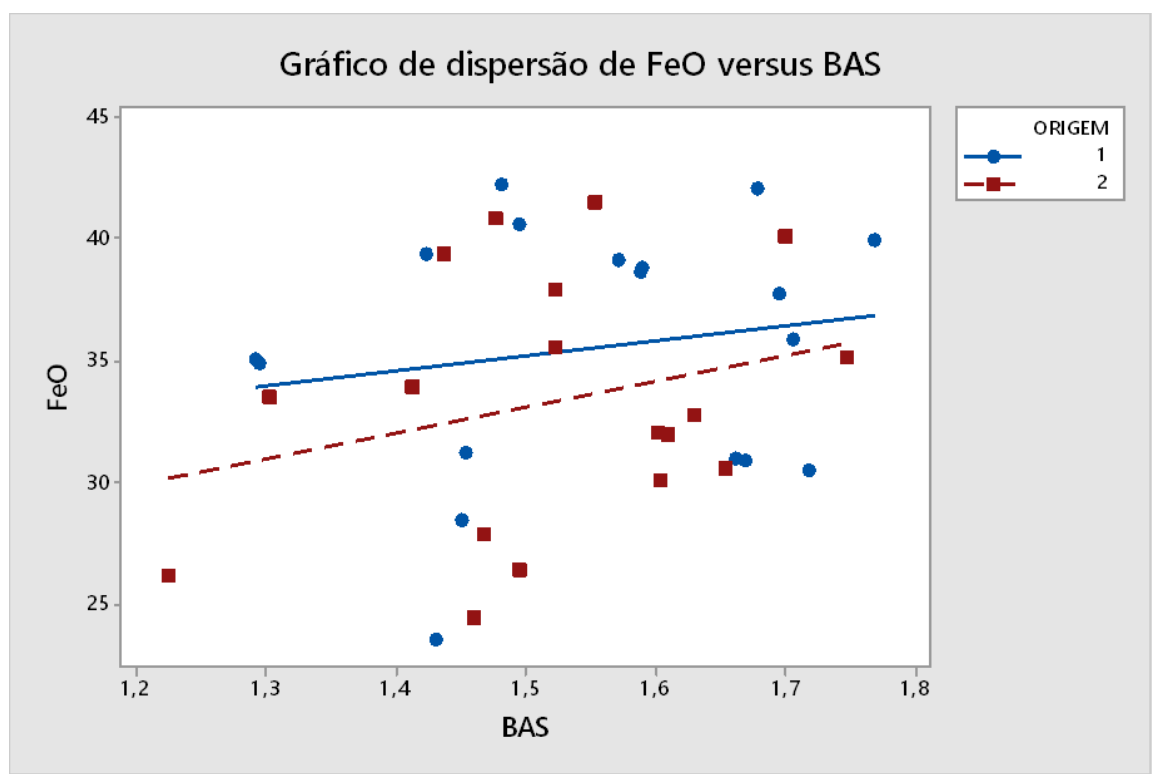

Figura 6: Influência da B2 no \%FeO da escória. (1- amostra de início de refino) (2-amostra final de refino). na escória.

Percebe-se que quanto maior a basicidade da escória, maior também é o FeO

Comparando as figuras 5 e 6 e as adições realizadas no FEA, a proposta de trabalho é de ajustar a basicidade binária B2 para 1,6 (ainda boa para espumação) com \%MgO de 9,5\%. Estes valores foram adotados visando manter um \%MgO que não fosse excessivo, o que poderia levar a retenção de gotas metálicas na escória.

Como resultado desta proposta, aumentou-se a adição de cal dolomítica em $31 \%$ para os dois aços e manteve-se a mesma adição de cal calcítica.

\subsection{Avaliação do efeito da mudança da prática de escória}

A partir da Figura 7 os resultados obtidos na prática anterior ( $\mathrm{B}=1.52$ e \%MgO de 8,9) são comparados com os resultados obtidos com B=1.62 e \%MgO de 9,9.
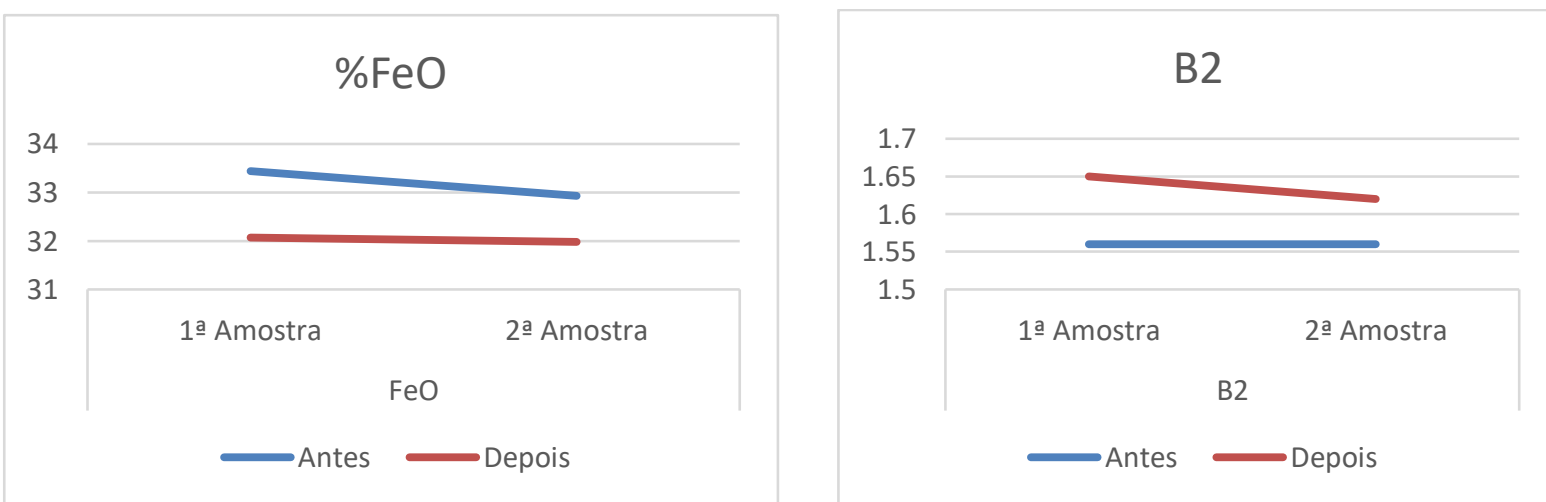

Figura 7: Evolução do FeO e B2 durante refino, para as duas práticas (antes das mudanças e depois das mudanças)

É possível observar que a nova prática conduziu à redução do $\mathrm{FeO}$, com a melhoria da retenção da escória e reversão do Fe para o banho, diminuindo o valor de B2. Isso foi obtido graças ao aumento da saturação de MgO na escória, como é possível 
ser verificado no Figura 8, calculada com o programa Thermo-Calc e o banco de dados TCOX7 [6]:

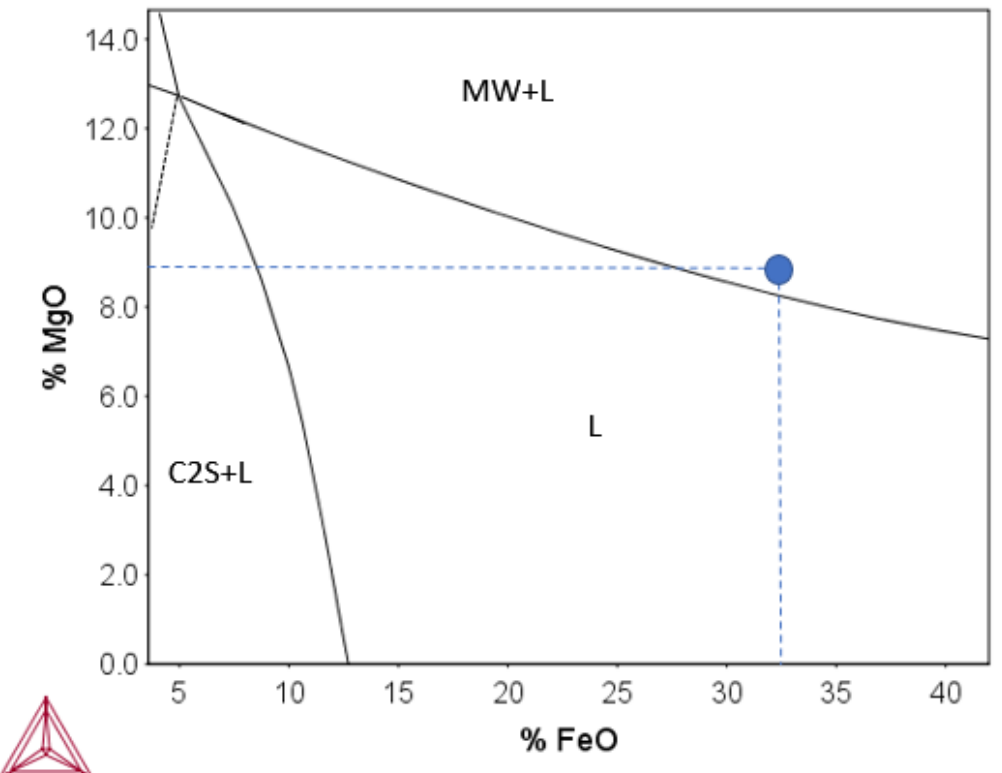

Figura 8 (a) Diagrama isopleta de equilíbrio de fases ("isothermal saturation diagram") para a escória média antes das mudanças realizadas. $\mathrm{B}=1,52, \mathrm{~T}=1570 \mathrm{C}, \% \mathrm{Al} 2 \mathrm{O} 3=8,5$. O ponto assinalado é a composição média das escórias de final de refino. A escória contém uma fração de sólidos adequada para promover boa espumação. ( $\mathrm{MW}=$ magnesiowustita, $\mathrm{C} 2 \mathrm{~S}=$ dicálcio silicato $\mathrm{L}=$ liquido).

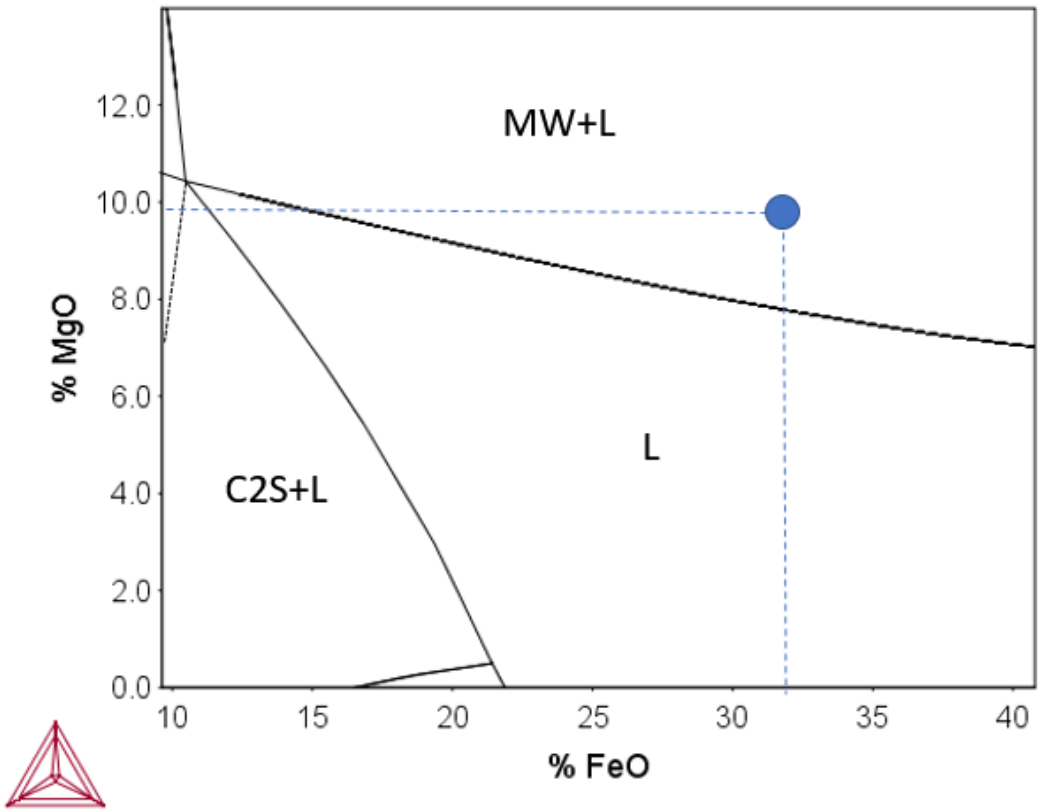

Figura 8 (b) Diagrama isopleta de equilíbrio de fases ("isothermal saturation diagram") para a escória média após as mudanças realizadas. $\mathrm{B}=1,62, \mathrm{~T}=1570 \mathrm{C}, \% \mathrm{Al} 2 \mathrm{O} 3=8,7$. O ponto assinalado é a composição média das escórias de final de refino. A escória continha, na média, pequena fração sólida. ( $\mathrm{MW}=$ magnesiowustita, $\mathrm{C} 2 \mathrm{~S}=$ dicálcio silicato $\mathrm{L}=$ liquido).

A Figura 9 apresenta os teores de $\mathrm{MgO}$ nas escórias antes e depois das mudanças de processo. 


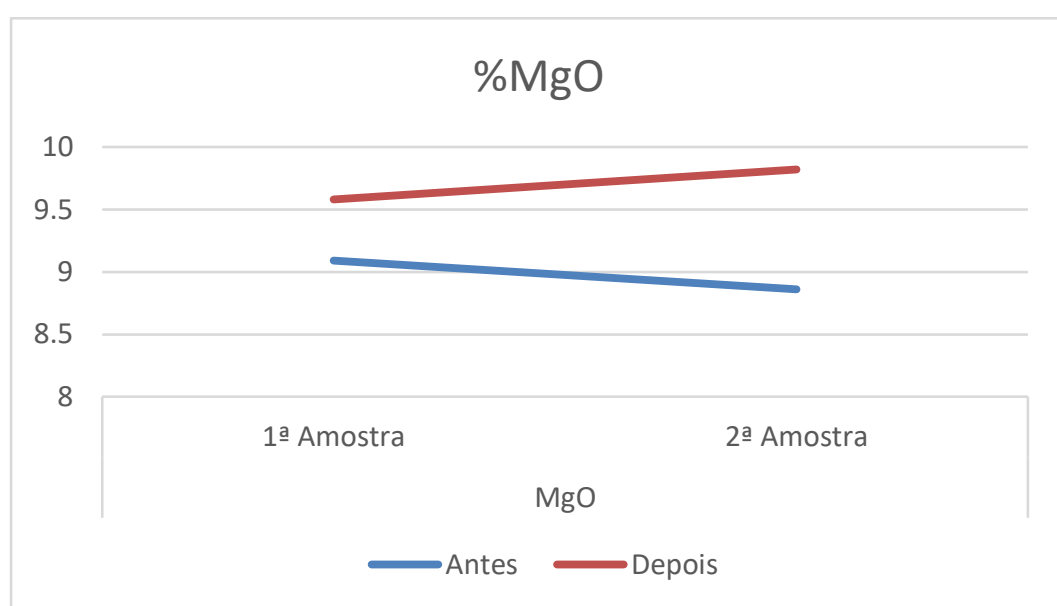

Figura 9: Evolução do MgO durante refino (antes das mudanças e depois das mudanças)

\subsection{Consumo de Energia e Rendimento}

A mudança no programa de adição de escorificantes resultou em uma redução de consumo de EE de $17 \mathrm{kWh} / \mathrm{t}$. Apesar do cálculo da variação do rendimento metálico não ser direto, uma vez que não se mediu os pesos de escória passante e restante e seus teores de $\mathrm{FeO}$ para cada corrida, foi verificada uma melhoria média de $0,08 \%$ entre o rendimento esperado e obtido pelo FEA.

\section{CONCLUSÃO}

É possível perceber que a análise das escórias foi melhorada com a alteração da receita de cal dolomítica em $31 \%$ se comparada à receita de adição original. Houveram ganhos em EE e no \% MgO, o que melhora a vida do refratário do FEA, o que não foi medido por conta da dificuldade de medição. O ganho em Energia elétrica foi de $17 \mathrm{kWh} / \mathrm{t}$. Além disso, apesar do cálculo do delta de RM não ser direto, uma vez que não se sabe a quantidade de escória perdida com cada \% de $\mathrm{FeO}$, foi visto uma melhoria de $0,08 \%$ no delta de rendimento esperado e obtido pelo FEA.

\section{REFERÊNCIAS}

1 T. A. Ávila. Condicionamento de escórias em Forno Elétrico a arco para otimização das condições de espumação da escória e refino do aço. 2011. Dissertação apresentada ao Curso de Pós graduação em Engenharia Metalúrgica da escória de Minas, UFMG.

2 J.A.T. Jones, B. Bowman, P.A. Lefrank, "Electric Furnace Steelmaking", in The Making, Shaping and Treating of Steel, R.J. Fruehan, Editor. 1998, The AISE Steel Foundation: Pittsburgh. p. 525-660.

3 Ito K, Fruehan RJ. Study on the foaming of $\mathrm{CaO}-\mathrm{SiO} 2-\mathrm{FeO}$ slags: Part I. Foaming parameters and experimental results. Metallurgical Transactions B. 1989;20B(August):509-14.

4 Ito $\mathrm{K}$, Fruehan RJ. Study of the foaming of $\mathrm{CaO}-\mathrm{SiO} 2-\mathrm{FeO}-\mathrm{Slags}$ Part II. Dimensional analysis and foaming in Iron and Steelmaking processes. Metallurgical Transactions B. 1989;20B(August):515-21.

5 E Pretorious, $\mathrm{H}$ Oltmann. Fundamentals of the EAF Process. LWB Refractories; 2011, disponível em http://etech.Iwbref.com/Downloads/ Theory/

Fundamentals\%20of\%20the\%20EAF\%20Process.pdf. [acesso em 04 abr 2016 
6 Andersson JO, Helander T, Höglund L, Shi P, Sundman B. Thermo-Calc \& DICTRA, computational tools for materials science. Calphad. 2002;26(2):273312. 